\title{
EVALUATION OF PHYTOCHEMICAL AND ANTIBACTERIAL PROPERTIES OF WHITE MULBERRY (Morus alba)
}

\author{
NURUL HUDA ABDUL WAHAB ${ }^{1,2}$, HOY ZHEN HAO $^{1}$ and SUZANA MISBAH ${ }^{1,3^{*}}$ \\ ${ }^{1}$ Faculty of Science and Marine Environment, Universiti Malaysia Terengganu, \\ 21030 Kuala Nerus, Terengganu, Malaysia \\ ${ }^{2}$ Advanced Nano Materials (ANoMa) Research Group, Universiti Malaysia Terengganu, \\ 21030 Kuala Nerus, Terengganu, Malaysia \\ ${ }^{3}$ Biological Security and Sustainability (BioSES) Research Interest Group, \\ Universiti Malaysia Terengganu, 21030 Kuala Nerus, Terengganu, Malaysia \\ "E-mail:suzana_m@umt.edu.my
}

Accepted 18 November 2020, Published online 25 December 2020

\begin{abstract}
Traditional Chinese Medicine is mainly derived from medicinal herbal plant sources, which are easily obtained and cheaper than modern medicines. One such plant used as a remedy to treat various illnesses is Morus alba, known as white mulberry. This study aimed to screen the phytochemicals of $M$. alba and examine the potential antibacterial activity against several pathogenic bacteria. Leaves, fruits, and stems of $M$. alba were extracted using three solvents of different polarities (hexane, ethyl acetate, methanol) to screen the presence of phytochemical constituents, followed by an evaluation of their antimicrobial potential. The qualitative phytochemical tests revealed that carbohydrates, flavonoids, tannins, saponins, steroids, coumarins, alkaloids, and terpenoids were detected in the crude extracts of M. alba. Extracts of ethyl acetate and methanol preparations were subjected to antibacterial susceptibility test using disk diffusion method against Bacillus sp., Staphylococcus aureus, Enterococcus faecalis, Klebsiella pneumoniae, Escherichia coli, and Salmonella sp. Interestingly, M. alba methanolic leaf extract showed noticeable antibacterial activity in a dose-dependent manner (concentration range 6.25-100\%) against all tested Gram-positive bacteria. Data of this study provide preliminary findings on the potential use of $M$. alba leaf for the treatment of infections caused by the Gram-positive bacteria.
\end{abstract}

Key words: Morus alba; Moraceae, phytochemicals, antibacterial, qualitative assessment

\section{INTRODUCTION}

Traditional Chinese Medicine (TCM) utilizes natural sources and various herbs in Chinese medical practice. The white mulberry or Morus alba is one such TCM herbal plant, which belongs to the major flowering group of the family Moraceae, along with other members; Morus nigra (black mulberry) and Morus ruba (red mulberry). Species of Morus can be found in subtropical and temperate regions, widely cultivated in Korea and Japan (Chan et al., 2016).

Most TCM herbal plants are produced in the form of crude extract containing a complex mixture of different phytochemicals. These include flavonoids, alkaloids, and phenolic acids commonly present in the Morus genus (Natić et al., 2015; Chan

* To whom correspondence should be addressed. et al., 2016). Phytochemical constituents derived from $M$. alba have been extensively investigated for biological properties. For instance, flavonoids from the branches of $M$. alba have been shown to contain a high antioxidant that scavenges superoxide radicals (Hussain et al., 2017), whereas polysaccharides of $M$. alba leaf improve flavonoid antioxidant activity (He et al., 2018). Polyphenols, such as (E)-resveratrol and moracin $\mathrm{M}$ extracted from M. alba stem have anti-inflammatory activity (Rivière et al., 2014). Moracins have also been reported to possess antifungal and antibacterial properties (Naik et al., 2015). Besides that, isolation of steroid compounds of $M$. alba stem bark; albosteroid, demonstrated effective antiulcer ability by diminishing gastric ulcer lesion of experimental rats (Ahmad et al., 2013). Research has also shown that the treatment of convulsion models rats with Morusin, a novel flavonoid glycoside isolated from 
M. alba was able to decrease seizures of epilepsy (Gupta et al., 2014).

To date, interest in developing therapeutic agents derived from TCM plant sources has increased due to the development of microbial resistance to the current antibiotics. Considerable efforts have been made to discover potential phytochemicals and secondary metabolites of TCM plants that may have antimicrobial properties. Considering M. alba is one of the TCM plants easily grown in Malaysia, the potential use of this plant as an antimicrobial source is economical. Thus, this study was carried out in order to determine the phytochemical constituents of $M$. alba and evaluate its potential antibacterial properties.

\section{MATERIALS AND METHODS}

\section{Plant materials}

Fresh M. alba leaves, stems, and fruits were collected from Subang Jaya, Selangor. The samples were washed and shaded dry at room temperature for five days before pulverized into a powder. The plant powder was then stored in sealed containers at $4^{\circ} \mathrm{C}$.

\section{Plant extraction}

Morus alba powder samples were dissolved in three different solvents with increasing polarity (hexane, ethyl acetate, and methanol) at room temperature using ultrasonic sonication technique (Elma D-78224 Singen Htw, Germany). The extracts were then concentrated using a rotary evaporator (Büchi Rotavap R-200 CH-9230, Switzerland) at $35-40^{\circ} \mathrm{C}$ under reduced pressure. Each extract was then weighed and stored at $4^{\circ} \mathrm{C}$.

\section{Phytochemical screening}

\section{Detection of carbohydrate (Fehling's Test)}

Plant extracts $(0.5 \mathrm{~g})$ were dissolved in distilled water and filtered. The filtrates were hydrolyzed with hydrochloric acid $(\mathrm{HCl})$ and subsequently neutralized with sodium hydroxide $(\mathrm{NaOH})$. Fehling's A and B solutions were added to the mixture. The formation of brick red precipitates indicated the presence of carbohydrates.

\section{Detection of flavonoid (Alkaline Reagent Test)}

Plant extracts $(0.5 \mathrm{~g})$ were treated with drops of $\mathrm{NaOH}$. The addition of a few drops of $\mathrm{HCl}$ caused decolorization of intense yellow which indicated the presence of flavonoids.

Detection of polyphenol and tannin (Ferric Chloride Test)

Ferric chloride (2-3 drops of 5\% solution) were added into $0.5 \mathrm{~g}$ plant extracts. The presence of phenols was shown by the formation of greenishblack or blue-green color.

Detection of saponin (Foam Test)

Plant extracts $(0.5 \mathrm{~g})$ were vigorously shaken with $2 \mathrm{~mL}$ distilled water. The formation of foam that lasted for $10 \mathrm{~min}$ indicated the presence of saponins.

Detection of steroid/triterpenoid (LiebermannBurchard Test)

Chloroform was added to the plant extract along with a few drops of sulphuric acid. The mixture was shaken and left at room temperature for a few minutes. The formation of red and yellow color indicated the presence of steroids and triterpenoids, respectively.

\section{Detection of coumarin}

Plant extracts $(0.5 \mathrm{~g})$ were treated with $3 \mathrm{~mL}$ of $10 \% \mathrm{NaOH}$. The formation of a yellow color indicated the presence of coumarins.

\section{Detection of alkaloid (Wagner's Test)}

Wagner's reagent (2-3 drops) were added to the plant extracts. The formation of brownish or reddish precipitate was an indication of the presence of alkaloids.

\section{Detection of protein (Biuret Test)}

Plant extracts $(0.5 \mathrm{~g})$ were treated with $4 \%$ $\mathrm{NaOH}$, followed by two drops of $1 \%$ cuprum sulphate. The presence of proteins was indicated by the formation of violet color.

\section{Detection of anthocyanin}

Plant extracts $(0.5 \mathrm{~g})$ were mixed with $2 \mathrm{~mL}$ of $2 \mathrm{~N} \mathrm{HCl}$. Anthocyanins were present when the pinkish-red solution turned purplish-blue after the addition of ammonia.

\section{Preparation of bacteria inoculum}

Bacteria isolates were obtained from the Microbiology Laboratory, Faculty of Science and Marine Environment, Universiti Malaysia Terengganu. These include three Gram-Positive bacteria; Bacillus sp., Staphylococcus aureus, and Enterococcus faecalis, and three Gram-negatives; Escherichia coli, Klebsiella pneumoniae, and Salmonella sp. Bacteria inoculum were prepared fresh by mixing bacteria colonies into $0.9 \% \mathrm{NaCl}$. Turbidity of each suspension was adjusted equivalent to $0.5 \mathrm{McF}$ arland before inoculated onto Mueller-Hinton agar (MHA).

\section{Determination of antibacterial activity}

Crude extracts of $M$. alba leaf, fruit, and stem prepared in ethyl acetate and methanol were 
subjected to antibacterial assay using the KirbyBauer disk diffusion method (Clinical and Laboratory Standards Institute et al., 2019). Each extract was serially diluted $(100 \%, 50 \%, 25 \%$, $12.5 \%, 6.25 \%, 3.12 \%, 1.56 \%$ and $0.78 \%$ ) and pipetted $(20 \mu \mathrm{L})$ onto $6 \mathrm{~mm}$ sterile discs. Each disc was firmly placed on MHA plates inoculated with bacteria. Experiments were carried out in triplicates for each plant extract. Standard antibiotic disc gentamicin $(10 \mathrm{mg} / \mathrm{mL})$ was used as a positive control, whereas, ethyl acetate and methanol were used as negative controls. The MHA plates were then incubated at $37^{\circ} \mathrm{C}$ overnight. The antibacterial activity demonstrated by $M$. alba extracts was recorded based on the diameter of clear inhibition zones on MHA plates.

\section{Statistical analysis}

Data of the bacterial growth inhibition zones were analyzed using Microsoft Excel and reported as means \pm standard deviation of the three replicates $(n=3)$ of each plant sample.

\section{RESULTS AND DISCUSSION}

\section{Phytochemical analysis}

A series of qualitative phytochemical screening was conducted on $M$. alba extracts (leaf, fruit, and stem) to determine the presence of metabolites. In our study, overall data showed that carbohydrates, flavonoids, tannins, saponins, steroids, coumarins, alkaloids, and terpenoids were present in $M$. alba crude extracts (Table 1). Most compounds are considered as semi-polar and polar due to the presence of more phytochemicals in ethyl acetate and methanol extracts. Regardless of the type of solvent used, carbohydrates were present in all $M$. alba extracts. Carbohydrates are sugar biomolecules that act as a vital source of energy for all living organisms. Our data are consistent with a previous report on the presence of carbohydrates in fruits and leaves of M. alba (He et al., 2018). This study also found that flavonoids are present in both methanolic and ethyl acetate of $M$. alba extracts. Flavonoids have been suggested as the primary bioactive molecule in M. alba (Ramesh et al., 2014; Chan et $a l ., 2016)$. The compound is semi or high polar due to the presence of hydroxyl $(-\mathrm{OH})$ and carbonyl $(\mathrm{C}=\mathrm{O})$ groups in the structural backbone.

Polyphenols, tannins, and saponins were also detected in all parts; leaf, fruit, and stem of M. alba, which correlates well with previous findings (Devi et al., 2013; Grajek et al., 2015). Polyphenols and tannins are general antioxidants that can serve as potential anticancer (Rivière et al., 2014). The presence of these compounds in $M$. alba suggests the plant as a great source of natural antioxidants. Besides that, M. alba was found to contain steroids, which correlates with previous data (Ahmad et al., 2013; Hussain et al., 2017). Furthermore, coumarins were detected in $M$. alba ethyl acetate and methanol extracts. Of note, this is the first report of detecting coumarin in $M$. alba fruits, rather than in the leaves and stems (de Oliveira et al., 2015; Chan et al., 2016).

Alkaloid has been reported as the main phytochemical in M. alba fruits (Chan et al., 2016). Findings from the current study, however, detected alkaloids only in the leaves and stem of $M$. alba. It is known that several factors such as light intensity, heat, high moisture, and oxygen reduce the stability of alkaloids (El-Sakka et al., 2010). We speculate improper storage of the plant samples leading to excessive moisture may have caused degradation of alkaloids in our fruit samples. Our study also detected terpenoids in methanol extract of both fruits and stems of $M$. alba, which correlates with previous reports (Grajek et al., 2015; Chan et al., 2016). Unfortunately, proteins and anthocyanins

Table 1. Phytochemical compounds of $M$. alba crude extracts

\begin{tabular}{|c|c|c|c|c|c|c|c|c|c|}
\hline \multirow{2}{*}{ Phytochemical } & \multicolumn{3}{|c|}{ Leaf } & \multicolumn{3}{|c|}{ Fruit } & \multicolumn{3}{|c|}{ Stem } \\
\hline & $\mathrm{H}$ & $\mathrm{EA}$ & $\mathrm{M}$ & $\mathrm{H}$ & EA & $\mathrm{M}$ & $\mathrm{H}$ & $\mathrm{EA}$ & M \\
\hline Carbohydrate & + & + & + & + & + & + & + & + & + \\
\hline Flavonoid & - & + & + & - & + & + & - & + & + \\
\hline Polyphenol and Tannin & - & + & + & - & + & + & - & + & + \\
\hline Saponin & - & + & + & - & - & + & + & - & + \\
\hline Steroid & + & + & + & + & + & - & + & - & - \\
\hline Coumarin & - & + & + & - & + & + & - & + & + \\
\hline Alkaloid & - & + & - & - & - & - & - & + & - \\
\hline Terpenoid & - & - & - & - & - & + & - & + & + \\
\hline Protein & - & - & - & - & - & - & - & - & - \\
\hline Anthocyanin & - & - & - & - & - & - & - & - & - \\
\hline
\end{tabular}

+ : Detected. - : Non-detected. H: Hexane. EA: Ethyl acetate. M: Methanol. 
Table 2. Antibacterial activity exhibited by the leaf, fruit, and stem of $M$. alba extracts

\begin{tabular}{|c|c|c|c|c|c|c|c|c|c|}
\hline \multirow{3}{*}{ Bacteria } & \multicolumn{9}{|c|}{ Diameter of inhibition zones $(\mathrm{mm})$} \\
\hline & \multirow{2}{*}{$\begin{array}{c}\begin{array}{c}\text { Positive } \\
\text { control }\end{array} \\
G\end{array}$} & \multicolumn{2}{|c|}{$\begin{array}{l}\text { Negative } \\
\text { control }\end{array}$} & \multicolumn{2}{|c|}{ Leaf } & \multicolumn{2}{|c|}{ Fruit } & \multicolumn{2}{|c|}{ Stem } \\
\hline & & $\mathrm{M}$ & EA & M & $\mathrm{EA}$ & M & $\mathrm{EA}$ & M & EA \\
\hline Bacillus sp. & $19.3 \pm 0.16$ & - & - & $10 \pm 0.12$ & - & - & - & - & $8 \pm 0.14$ \\
\hline Staphylococcus aureus & $21.8 \pm 0.08$ & - & - & $11 \pm 0.04$ & - & $8 \pm 0.07$ & - & $8 \pm 0.16$ & $7 \pm 0.23$ \\
\hline Enterococcus faecalis & $15.4 \pm 0.05$ & - & - & $12 \pm 0.09$ & - & - & - & - & - \\
\hline Klebsiella pneumoniae & $18.2 \pm 0.13$ & - & - & - & - & - & - & - & - \\
\hline Salmonella sp. & $16.9 \pm 0.22$ & - & - & - & - & - & - & - & - \\
\hline Escherichia coli & $17.1 \pm 0.30$ & - & - & - & - & - & - & - & - \\
\hline
\end{tabular}

G: gentamicin. M: methanol. EA: ethyl acetate. - : No antibacterial activity.

Values are the means of diameter \pm standard deviation.

were not detected in any of $M$. alba extracts. This could be due to the limited amount produced or they could have been degraded by physical factors such as $\mathrm{pH}$ and high temperatures. These factors have been shown to affect their stability (Aramwit et al., 2010), thus appropriate storage of the plant extracts is vital to avoid degradation.

\section{Antibacterial activity}

The leaf, fruit, and stem of $M$. alba extract prepared in methanol and ethyl acetate, which were found high in phytochemical constituents were subsequently screened for antibacterial activity using the Kirby-Bauer disk diffusion method. Based on the results, $M$. alba leaf extracted in methanol inhibited the growth of all three Grampositive bacteria; Bacillus sp., S. aureus, and E. faecalis at $100 \%$ concentration (Table 2). The largest inhibition zone was seen in E. faecalis $(12 \pm 0.09 \mathrm{~mm})$, followed by $S$. aureus $(11 \pm 0.04 \mathrm{~mm})$ and Bacillus sp. (10 $\pm 0.12 \mathrm{~mm})$. Further dilution of the extract down to $6.25 \%$ concentration showed an inhibition towards the bacterial growth in a concentration-dependent manner.

Findings of this study correlate well with others, demonstrating $M$. alba methanolic leaf extract can inhibit the growth of $S$. aureus and E. faecalis (Sheikhlar et al., 2013; Cui et al., 2019). Ethanolic extract of $M$. alba leaf has been previously shown to be more effective against fungi, and capable of inhibiting the growth of Gram-negative bacteria (Omidiran et. al., 2012; de Oliveira et al., 2015). This highlights the importance of $M$. alba leaves due to the potential presence of antimicrobial components against a wide range of microorganisms. On the contrary, ethyl acetate extracts of $M$. alba leaf did not show any inhibition activity. This could be due to the organic solvent used, which produced different bioactive phytochemical constituents.

Apart from the leaf, the fruit and stem of M. alba have been previously investigated for antimicrobial properties with various findings. In this study, we found that the fruit and stem methanolic extracts of M. alba demonstrated milder antibacterial activity than the methanolic leaf. They inhibited the growth of $S$. aureus (at $100 \%$ concentration) with a reduced diameter of inhibition zones compared to the leaf extract (Table 2). Fruit extract of $M$. alba has been reported to contain high antioxidants and possess antibacterial activity against $B$. subtilis, $S$. aureus, E. coli, and Salmonella typhimurium (Dimitrijevic et al., 2014). This is also true for M. alba stem extract which was able to inhibit the growth of oral pathogens (Zafar et al., 2013). Similar observations were obtained in this study with $M$. alba stem prepared in ethyl acetate, which was shown to be effective towards inhibiting the growth of Bacillus sp. and S. aureus at $100 \%$ concentration.

Environmental factors such as temperature, humidity, and the location of $M$. alba cultivations may contribute to the quality of $M$. alba leaves, hence the presence of bioactive constituents (Hao et al., 2018). Besides, the extraction method and polarity of solvents used are equally important. The different polarity of solvents results in the extraction of different types of phytochemical constituents with varying amount and level of stability. Of note, the test bacteria used in this study were those commonly associated with various forms of human infections. Thus, the demonstration of antibacterial activity of $M$. alba particularly towards the Grampositive bacteria suggests that the plant serves as a potential source of bioactive substances, useful for the development of therapeutic agents against pathogenic bacteria.

\section{CONCLUSION}

Several phytochemical constituents including carbohydrates, flavonoids, tannins, saponins, steroids, coumarins, alkaloids, and terpenoids were detected in methanol and ethyl acetate extracts of M. alba. The methanolic extract of M. alba, 
particularly in the leaf has demonstrated a noticeable antibacterial activity towards the Grampositive bacteria in a dose-dependent manner. This finding suggests that $M$. alba leaf possesses a substantial level of bioactive components that play a role in inhibiting the growth of Gram-positive bacteria. Further investigation involving isolation and identification of the extract components is essential for the development of a potential therapeutic agent against Gram-positive bacterial infection.

\section{ACKNOWLEDGEMENTS}

The authors would like to thank the Faculty of Science and Marine Environment, Universiti Malaysia Terengganu for providing the research fund and facilities to carry out this project.

\section{REFERENCES}

Ahmad, A., Gupta, G., Afzal, M., Kazmi, I. \& Anwar, F. 2013. Antiulcer and antioxidant activities of a new steroid from Morus alba. Life Sciences, 92(3): 202-210.

Aramwit, P., Bang, N. \& Srichana, T. 2010. The properties and stability of anthocyanins in mulberry fruits. Food Research International, 43(4): 1093-1097.

Chan, E.W.C., Lye, P.Y. \& Wong, S.K. 2016. Phytochemistry, pharmacology, and clinical trials of Morus alba. Chinese Journal of Natural Medicines, 14(1): 17-30.

Clinical and Laboratory Standards Institute. 2019. Performance Standards for Antimicrobial Susceptibility Testing. 29th Ed. Clinical and Laboratory Standards Institute, Wayne.

Cui, H., Lu, T., Wang, M., Zou, X., Zhang, Y., Yang, X., Dong, Y. \& Zhou, H. 2019. Flavonoids from Morus alba L. Leaves: Optimization of extraction by response surface methodology and comprehensive evaluation of their antioxidant, antimicrobial, and inhibition of $\alpha$-amylase activities through analytical Hierarchy process. Molecules, 24(13): E2398.

de Oliveira, A.M., Matheus da, S.M., da Silva, G.C., Edeltrudes de, O.L., Paloma Lys, D.M., Patrícia Maria, G.P., Ivone Antônia, D.S. \& Thiago, H.N. 2015. Evaluation of toxicity and antimicrobial activity of an ethanolic extract from leaves of Morus alba L. (Moraceae). Evidence-Based Complementary and Alternative Medicine, 2015: 513978.
Devi, B., Sharma, N., Kumar, D. \& Jeet, K. 2013. Morus alba Linn: A phytopharmacological review. International Journal of Pharmacy and Pharmaceutical Sciences, 5(Suppl. 2): 14-18.

Dimitrijević, D.S., Kostić, D.A., Stojanović, G.S., Mitić, S.S., Mitić, M.N. \& Đorđević, A.S. 2014. Phenolic composition, antioxidant activity, mineral content and antimicrobial activity of fresh fruit extracts of Morus alba L. Journal of Food and Nutrition Research, 53(1): 22-30.

El-Sakka, M.A. 2010. Phytochemistry (3) Alkaloids. 3rd Ed. Al Azhar University, Cairo.

Grajek, K., Wawro, A. \& Kokocha, D. 2015. Bioactivity of Morus alba L. extracts - An overview. International Journal of Pharmaceutical Sciences and Research, 6(8): 3110.

Gupta, G., Dua, K., Kazmi, I. \& Anwar, F. 2014. Anticonvulsant activity of Morusin isolated from Morus alba: Modulation of GABA receptor. Biomedicine and Aging Pathology, 4(1): 29-32.

Hao, J.Y., Wan, Y., Yao, X.H., Zhao, W.G., Hu, R.Z., Chen, C., Li, L., Zhang, D.Y. \& Wu, G.H. 2018. Effect of different planting areas on the chemical compositions and hypoglycemic and antioxidant activities of mulberry leaf extracts in southern China. PLoS ONE, 13(6): 1-15.

He, X., Fang, J., Ruan, Y., Wang, X., Sun, Y., Wu, N., Zhao, Z., Chang, Y., Ning, N., Guo, H. \& Huang, L. 2018. Structures, bioactivities and future prospective of polysaccharides from Morus alba (white mulberry): A review. Food Chemistry, 245: 899-910.

Hussain, F., Rana, Z., Shafique, H., Malik, A. \& Hussain, Z. 2017. Phytopharmacological potential of different species of Morus alba and their bioactive phytochemicals: A review. Asian Pacific Journal of Tropical Biomedicine, 7(10): 950-956.

Naik, R., Harmalkar, D.S., Xu, X., Jang, K. \& Lee, K. 2015. Bioactive benzofuran derivatives: Moracins A-Z in medicinal chemistry. European Journal of Medicinal Chemistry, 90: 379-393.

Natić, M.M., Dabić, D., Papetti, A., Fotirić Akšić, M.M., Ognjanov, V., Ljubojević, M. \& Tešić, Ž.L. 2015. Analysis and characterisation of phytochemicals in mulberry (Morus alba L.) fruits grown in Vojvodina, North Serbia. Food Chemistry, 171: 128-136.

Omidiran, M.O., Baiyewu, R.A., Ademola, I.T. Fakorede, O.C., Toyinbo, O.J. \& Adekunle, E.A. 2012. Phytochemical analysis, nutritional composition and antimicrobial activities of white mulberry (Morus alba). Pakistan Journal of Nutrition, 5: 456-460. 
Ramesh, H.L., Sivaram, V. \& Yogananda Murthy, V.N. 2014. Antioxidant and medicinal properties of mulberry (Morus sp.): A Review. World Journal of Pharmaceutical Research, 3(6): 320343.

Rivière, C., Krisa, S., Péchamat, L., Nassra, M., Delaunay, J.C., Marchal, A., Badoc, A., WaffoTéguo, P. \& Mérillon, J.M. 2014. Polyphenols from the stems of Morus alba and their inhibitory activity against nitric oxide production by lipopolysaccharide-activated microglia. Fitoterapia, 97: 253-260.
Sheikhlar, A., Alimon, A.R., Daud, H.M, Saad, C.R. \& Shanagi, H. 2013. Screening of Morus alba, Citrus limon and Trigonella foenum-graecum extracts for antimicrobial properties and phytochemical compounds. Journal of Biological Sciences, 13: 386-392.

Zafar, M.S., Muhammad, F., Javed, I., Akhtar, M., Khaliq, T., Aslam, B., Waheed, A., Yasmin, R. \& Zafar, H. 2013. White mulberry (Morus alba): A brief phytochemical and pharmacological evaluations account. International Journal of Agriculture and Biology, 15(3): 612-620. 